IFN Working Paper No. 751, 2008

\title{
Democracy, Autocracy and the Likelihood of International Conflict
}

Thomas Tangerås 


\title{
Democracy, autocracy and the likelihood of international conflict*
}

\author{
Thomas P. Tangerås \\ Research Institute of Industrial Economics (IFN) \\ P.O. Box 55665, SE-102 15 Stockholm, Sweden \\ E-mail: thomas.tangeras@ifn.se \\ Homepage: www.ifn.se/thomast
}

June 12,2008

\begin{abstract}
This is a game-theoretic analysis of the link between regime type and international conflict. The democratic electorate can credibly punish the leader for bad conflict outcomes, whereas the autocratic selectorate cannot. For the fear of being thrown out of office, democratic leaders are $(i)$ more selective about the wars they initiate and (ii) on average win more of the wars they start. Foreign policy behaviour is found to display strategic complementarities. The likelihood of interstate war, therefore, is lowest in the democratic dyad (pair), highest in the autocratic dyad with the mixed dyad in between. The results are consistent with empirical findings.
\end{abstract}

JEL Classification: D72, D74, D82.

Keywords: Democracy, autocracy, war, Maximal Equilibrium.

*I am indebted to Harry Flam, Joseph Harrington and Johan Stennek as well as seminar participants at IFN and the University of Sydney for their helpful comments. 


\section{Introduction}

One of the most robust findings in the study of international politics is that the likelihood of war between two democracies is smaller than the likelihood of war between two countries of which at least one is autocratic. ${ }^{1,2}$ Bremer (1992) calculates the historic frequency of war between the dyads (pairs) of non-democratic states to 0.70 , decreasing to 0.18 for dyads of which one country was democratic and further to 0.05 for the democratic dyads (all frequencies multiplied by 1000). The finding that democracies are more peaceful towards each other than towards non-democracies, extends well beyond the observation that democracies rarely fight one another. ${ }^{3}$ There appears to be a general relationship between regime type and foreign policy behaviour (Leeds and Davis, 1999). For example, democracies tend to be involved in militarized dispute (including war) with each other less often than with non-democracies (Maoz and Abdolali, 1989).

This paper investigates within a game-theoretic framework how nations' decisions to engage in international conflict depends on the regime type. Two state leaders simultaneously and independently decide whether to attack the other country. The losing country is forced to pay a penalty to the winner. The prospect of additional spending is what creates the incentive for initiating war. The ruler does not have to bear the direct cost of conflict and therefore has a tendency to engage in conflict too often.

The game is an agency problem between the influential members of the polity or the selectorate (Shirk, 1993) and the state leader. The principal (the selectorate) must design policies so as to prevent the agent (the leader) from abusing power for his own purposes. The principal can use postconflict reselection probabilities to discipline behaviour since the leader derives rent from holding

\footnotetext{
${ }^{1}$ The first empirical report on the connection between regime type and likelihood of interstate conflict was Babst (1964). Some have proposed that there is no direct link between regime type and conflict. Rather, democracy proxies some other fundamental determinant, such as contiguity (Huntington, 1989), common alliance bonds (Ray, 1989), political stability (Huth and Russett, 1993), wealth (Mueller, 1989) or economic growth (Maoz and Russett, 1992). However, the degree of democratization has been shown to significantly affect the likelihood of conflict even after controlling for these factors, indicating a separate role for democracy (Bremer, 1992; Maoz and Russett, 1992 , 1993; Oneal et.al., 1996; Ward et.al., 2007). Some have argued that political similarity is what matters for conflict (Werner, 2000). For example, similar types of autocracies are less likely to be involved in militarized disputes than mixed autocracies (Peceny et.al, 2002).

${ }^{2}$ The most widely used data source for indicators of the degree of democratization in regimes is the Polity data set compiled by Gurr (1974) and subsequently updated. An indicator of autocracy and democracy is constructed based on measures of executive recruitment, executive constraints and political competition.

${ }^{3}$ Modern history has recorded very few instances of wars fought between democracies. Chan (1984) finds merely one war onset between democracies in the period 1816-1980, the Franco-Thai war of 1940. Gurr (1974), covering roughly the same time-span, identifies two wars between democratic states, the Spanish-American war of 1898 and the Second Kashmir war of 1965.
} 
office. Unfortunately, there are no means by which the principal can commit to a policy. The admissible reselection probabilities are required to be post-conflict rational, i.e., time-consistent.

The difference between democracy and autocracy lies here in the set of credible reselection policies. In all regimes, post-conflict political competition leads to full convergence in the platforms of the incumbent and the challenger(s). Hence, the only reason to replace the incumbent would be to punish him for past opportunistic behaviour. In autocracy, the ruler is never up for reselection. He can be ousted only at considerable cost and individual risk to anyone who purports to do so. Hence, the only time-consistent policy in autocracy is to reselect the ruler independently of past behaviour. In democracy, on the other hand, the leader is constantly evaluated in general elections. Any member of the electorate can cast her ballot in the incumbent's disfavour at no cost and is at no personal risk. Since all contestants offer identical policies, replacing the leader is individually rational. Hence, all reelection policies are credible in democracy.

The democratic electorate's superior ability to punish the leader holds the implication that the state leader in democracy will be comparatively less inclined to attack a foreign country, in the sense that it requires a higher military capability in order to do so. The democratic leader has to face the danger of being ousted, whereas the dictator knows he will never be punished for any foreign policy endeavour. Consequently, the model predicts that democratic leaders face a larger post-conflict risk of being replaced than autocratic leaders. This is well in line with the existing evidence (e.g. Bueno de Mesquita et.al., 1992 and 2003; Bueno de Mesquita and Siverson, 1995). Second, democracies are less aggressive than autocracies (Rousseau et.al., 1996). Third, one would expect democracies on average to win more of the wars they start than autocracies. Even this seems to be an empirical regularity (Bueno de Mesquita and Siverson, 1995; Reiter and Stam, 1998).

A key result of the paper is that foreign policy behaviour displays strategic complementarities: the more pacific a country is perceived to be in its foreign relations, the less likely it is to be attacked by a foreign power. This can be explained as follows. Each state leader knows his country will be attacked if and only if the adversary is sufficiently powerful. A pacification of the adversary is beneficial because war can now be avoided in circumstances under which it would most likely have been lost. However, the only way to take advantage of this opportunity is for a nation itself to abstain from the use of force. As democracies tend to be more pacific than autocracies in their 
international relations, strategic complementarity implies that the most dangerous dyad is the autocratic one and the most pacific dyad is the democratic one, with the mixed dyad somewhere in between. In addition, the likelihood of war is increasing in the benefit of winning and decreasing in the cost of losing the war, the benefit of holding office and the direct cost of warfare.

This is the first theoretical model of international conflict which jointly reproduces four empirical regularities: $(i)$ democratic dyads are more pacific than other dyads; $(i i)$ democracies are more selective about the wars they initiate; (iii) democracies on average win more of the wars they start and $(i v)$ political survival depends on conflict outcomes.

Jackson and Morelli (2007) analyse a model in which the leader in each country is biased in favour of conflict as he has a (weakly) larger benefit-cost ratio of war than the country as a whole. The main result is that two unbiased leaders always will make transfers to avoid war if they can commit not to go to war after the transfer has been made. Political bias may or may not lead to conflict, as it makes a leader more aggressive, but will also induce the opponent to accept a higher transfer. Which effect dominates, depends on the conflict technology. The incentive for going to war is independent of the political bias in the target country. It follows that a democracy (unbiased leadership) is equally likely to attack a democracy as it is to attack an autocracy (biased leadership) in the absence of transfers. ${ }^{4}$ The Jackson and Morelli (2007) model, therefore, cannot explain the observed pattern of behaviour in the absence of transfers. The present paper analyses conflict under the plausible assumption that transfers are impossible. Democracies are found to be comparatively less likely to attack a fellow democracy, since democracies are more docile than autocracies and foreign policy decisions are strategic complements.

Levy and Razin (2004) consider a model in which state leaders are privately informed about the benefits of conflict. The decision whether to engage in conflict is assumed to be taken by the public in democracy, but delegated to the leader if the regime is non-democratic. In autocracy, the ruler cannot credibly convey his strength to the adversary prior to conflict, whereas the democratic ruler can. Hence, autocracies tend to initiate conflict too often. By assumption, decisions are strategic complements, hence the democratic dyad is the most pacific.

The present paper considers how post-conflict events may shape the incentives of the political

\footnotetext{
${ }^{4}$ Bester and Wärneryd (2006) analyse the extent to which transfers can be used to minimize conflict when the two parties are asymmetrically informed about each other's strength. A main result is that conflict cannot always be fully avoided, even when unrestrained divisions of the surplus can be made.
} 
leadership. There is ample evidence to suggest that the political survival of leaders depends on conflict outcomes, see the above references. Rational leaders should foresee this possibility when deciding on policy. If the removal of a democratic leader is less costly than dismantling an autocrat, the democratic leader should be comparatively selective about the conflicts in which to engage. Since conflict decisions are strategic complements (this is derived, rather than assumed), democratic dyads are more pacific. Conflict decisions probably depend both on pre- and postconflict incentives. One may therefore view the present analysis and Jackson and Morelli (2007) and Levy and Razin (2004) as complementary, each emphasizing different aspects of democracy. In addition, I derive a few results not found in the other two. In particular, political survival of the leader is endogenous and depends on regime type and conflict outcomes.

Bueno de Mesquita et.al. (1999 and 2003) also stress the importance of post-conflict events for international policy. In their model, the incumbent secures his reselection by satisfying a critical mass of the selectorate, the winning coalition. The larger is the winning coalition, the more will the incumbent rely on public goods provision than private benefits for survival. Conflict outcomes are public goods by assumption. Therefore, the effort devoted to warfare is increasing in the size of the winning coalition. If democracies have larger winning coalitions than autocracies, democracies devote more effort to warfare and win more of the wars they are engaged in than autocracies. There are no general results concerning coalition size (regime type) and war initiation. The present paper therefore adds to Bueno de Mesquita et.al. (1999 and 2003) results by demonstrating that democracies are more docile than autocracies, all else equal. ${ }^{5}$

\footnotetext{
${ }^{5}$ Baliga et.al. (2007) extend Bueno de Mesquita et.al. (1999 and 2003) to include so-called limited democracies. In a limited democracy, the leader by assumption can secure his political survival by appealing to a hawkish minority. As a result, conflict is more likely the more limited democracies are involved in a dispute. Downs and Rocke (1994) are the first to view conflict as an agency-theoretic problem between the public (the principal) and the leadership (the agent). The study is partial in the sense that the strategic interplay between belligerent states is ignored. They make no formal distinction between autocracies and democracies, but expect information asymmetries between the leader and the public to be more severe in autocracies than democracies. It is probably true that the general public is better informed about policy in democracies than autocracies due to the existence of a free press, political opposition and so on. However, it is generally not the public who makes or breaks a dictator, it is an influential elite. Whether the autocratic elite is more or less informed about policy than the general public in democracy, is not so obvious. Garfinkel (1994) studies complementarities in military investments across regimes, but does not investigate nations' incentives for declaring war. The build-up of military power is important for understanding international conflict, but does not give a complete picture. Regime type significantly affects the likelihood of conflict even after controlling for military expenditures (e.g., Bremer, 1992; Maoz and Russett, 1993; Oneal et.al., 1996; Rousseau et.al., 1996). The present analysis treats military capability as exogenous and emphasizes regime type and the incentives for engaging in conflict. Bueno de Mesquita and Lalman (1992) is the first theoretical analysis of the interplay between regime type and interstate war. The analysis rests on two assumptions which do not seem to hold up to empirical scrutiny. First, it is assumed that democratic leaders would rather capitulate outright than fight a war on their home soil (Reiter and Stam, 1998). Second, the fear of exploitation leads democracies to launch preemptive strikes against autocratic enemies (Reiter, 1995). Here,
} 
The remainder of the paper is organized as follows. Section 2 presents the model. Section 3 analyses the incentives of the head of state for engaging in conflict, whereas Section 4 addresses the same issue from the viewpoint of the selectorate and derives the optimal time-consistent policy. Section 5 characterizes and analyses the equilibria of the game. Finally, section 6 concludes.

\section{The model}

Two countries, home and foreign, are involved in a militarized dispute with one another. The state leaders simultaneously decide whether to engage in conflict (wage war) with the other country. Conflict arises if at least one of the antagonists initiates it.

The likelihood $p(\boldsymbol{\theta})$ that the home country wins the conflict depends on the pair of military capabilities $\boldsymbol{\theta}=\left(\theta, \theta^{\prime}\right)$, where $\theta$ is the home country's military capability and $\theta^{\prime}$ the military power of the adversary. The probability of winning a conflict is increasing in own military capability, $p_{\theta}(\boldsymbol{\theta})>0$, and decreasing in the opponent's military capability, $p_{\theta^{\prime}}(\boldsymbol{\theta})<0$ (subscripts on functions denote partial derivatives throughout). Military capability is exogenously given and assumed to be private information to the leadership in each country. However, it is commonly known that $\theta$ and $\theta^{\prime}$ are independently and identically distributed on the interval $\Theta=[\underline{\theta}, \bar{\theta}]$ according to the continuous density function $f(\cdot)>0$ and cumulative distribution function $F(\cdot)$, with $F(\underline{\theta})=0$.

Each country is endowed with exogenous income $I$. The incentive for waging war stems from the winner's possibility of expropriating resources from the loser. The value of winning the war in terms of net additional income is $B>0$, and the cost to the loser is $L \in(0, I)$, with $B \neq L$ in general. ${ }^{6}$ The inhabitants of the country incur a cost $K$ of warfare, except the ruler who does not face any direct costs of warfare. As will be apparent below, the asymmetric distribution of costs bears with it the implication that the ruler tends to wage war too often.

The political regime $R$ is either democratic, $R=D$, or autocratic, $R=A$. In the democratic regime, the leader is selected by majority voting in general elections and in competition with

I employ the realistic assumption that war is better than outright capitulation, and any artificial first or second mover advantage is removed by the assumption that players move simultaneously. Other models of conflict include Richards et.al. (1993), Smith (1993), Leeds (1999) and Hess and Orphanides (1995, 2001), all of whom analyse state leaders' incentives for engaging in diversionary international warfare. None of them perform a comparative analysis across regimes.

${ }^{6}$ Symmetry on resources and on the distribution of military capabilities is introduced mainly for notational convenience. All that is required for the results to go through is identical lower bounds $\underline{\theta}$ on the two countries' military capability. 
multiple contestants. There are many types of dictatorships, ranging from kleptocratic or "tinpot" regimes such as Zaire under Mobutu, Noriega's Panama or the Philippines under Marcos, via totalitarian regimes such as Nazi Germany or Stalin's Russia, to tyrannies such as Pinochet's Chile. ${ }^{7}$ Although these dictatorships vary in nature and scope, they all share the feature that the leader is not up for reelection. The dictator can be replaced only at considerable cost and personal risk to anyone who purports to do so. As in democracy, succession might be a political fight between multiple contestants manoeuvring to gain support from a majority of the selectorate (Shirk, 1993). The autocratic selectorate, however, generally consists of a small and influential elite. Hence, the power base of the selected autocrat might differ a lot from that of an elected democratic leader. Consequently, the ability and incentives for replacing a leader might vary across regimes. Denote by $\phi^{R P}$ the probability that the ruler in the home country is reselected conditional on the regime type $R \in\{D, A\}$ and on a pacific outcome of the conflict game, and let $\phi^{R W}$ and $\phi^{R L}$ be the reselection probabilities following a win and defeat, respectively, under regime type $R .^{8}$ Write $\Phi^{R}=\left\{\phi^{R P}, \phi^{R W}, \phi^{R L}\right\}$ and $\Phi^{R^{\prime}}$ the vector of reselection probabilities in the home country and the foreign country, respectively. As the leader tends to go to war too often, the selectorate could use the reselection probabilities as a disciplining device against the leader. This might work owing to the value $b>0$ attached by the leader to remaining in office.

The present game is an agency problem in which the uninformed principal (the selectorate) delegates to an informed agent (the leader) the decision to engage in conflict (Downs and Rocke, 1994). The principal is constrained by incomplete contracting; the only available instrument is the set of reselection probabilities. Moreover, the principal lacks the ability to commit to the contract it proposes. The reselection probabilities are credible only to the extent they are post-conflict rational. Hence, the selectorate is constrained to offering time-consistent punishment strategies. I assume that $\Phi^{R}$ and $\Phi^{R \prime}$ are common knowledge, although we only need to assume that they are correctly anticipated in equilibrium.

Post-conflict disposable income is equal to $X \in\{I-L, I, I+B\}$, independently of whether

\footnotetext{
${ }^{7}$ The examples are from Wintrobe (1998). He classifies dictatorships along two dimensions: repression of the subjects and loyalty to the ruler. The tinpot utilises just enough repression and buys just enough loyalty to stay in power and extract maximum rents. The totalitarian maximises power by creating a highly repressive regime with extremely loyal subjects sustained by a costly bureaucratic system. The tyrant relies on repression alone. Finally, the timocrat (of which there are few historical examples) focuses on loyalty to remain in power.

${ }^{8}$ In principle, reselection probabilities could depend even on the regime type $R^{\prime} \in\{D, A\}$ of the foreign country and on who initiated the conflict. We assume that the selectorates cannot observe who initiated the conflict. The selectorate cannot benefit from conditioning the reselection probability on the foreign regime type, see below.
} 
the incumbent is reselected or replaced. Moreover, political competition in both regimes assures that the challengers and the incumbent all position themselves exactly at the location at which they are ensured support from at least half of the selectorate, i.e., the median location. Thus, post-conflict spending is independent of the identity of the post-conflict leader. As the identity of the "median selector" tends to vary across regime types, so will equilibrium spending. To simplify matters and highlight the effects of the replacement, all differences are assumed away. The entire population is homogenous with disposable income $X$ spent on a public good equally beneficial to all. To simplify even further, all economic agents are assumed risk neutral. ${ }^{9}$

The timing of the game is as follows. Nature draws capability $\boldsymbol{\theta}$, and the rulers learn their own capability. Second, the selectorates in the two countries announce a vector of reelection probabilities $\Phi^{R}$ and $\Phi^{R^{\prime}}$, respectively. Next, the game moves into the conflict stage. A strategy at the conflict stage is a mapping from the set of types $\Theta$ into (a potential mix of) the set of actions \{"attack", "remain pacific"\}, conditional on the leaders' assessment of the actions in the foreign country and its belief about future reselection prospects and expected income. Reselection takes place immediately after the conflict stage.

The equilibrium concept applied is that of Bayesian Nash Equilibrium (BNE). A set of strategies constitutes a BNE if beliefs and actions are consistent: the optimal actions of a country, given its beliefs about the actions of the adversary, correspond with the beliefs that the adversary holds about its enemy's actions and vice versa.

\section{The ruler}

Suppose the ruler in regime $R$ holds the subjective belief that his adversary will remain pacific with probability $q^{\prime}(z)$ as a function of military capability $z \in \Theta$. If the ruler remains pacific with probability $q$, his expected utility is given by

$$
\begin{aligned}
V\left(\theta, q, q^{\prime}(z), \Phi^{R}\right)= & \int_{\Theta}\left[q q^{\prime}(z)\left(I+\phi^{R P} b\right)+\left(1-q q^{\prime}(z)\right)\left(p(\theta, z)\left(I+B+\phi^{R W} b\right)\right.\right. \\
& \left.\left.+(1-p(\theta, z))\left(I-L+\phi^{R L} b\right)\right)\right] d F(z)
\end{aligned}
$$

With probability $q q^{\prime}(z)$ peace prevails, income remains at $I$ and the ruler is reselected with probability $\phi^{R P}$. Otherwise war breaks out, is won with probability $p(\theta, z)$ and lost with probability

\footnotetext{
${ }^{9}$ The assumption of risk-neutrality is innocuous, any utility function strictly increasing in wealth will do.
} 
$1-p(\theta, z)$. In case of a win, income increases to $I+B$ and the reselection probability is $\phi^{R W}$, in case of a loss income falls to $I-L$ and the reselection probability is $\phi^{R L}$. Differentiate with respect to $q$ to get

$$
v\left(\theta, q^{\prime}(z), \Phi^{R}\right)=\int_{\Theta} q^{\prime}(z)\left[p(\theta, z)\left(B+\left(\phi^{R W}-\phi^{R P}\right) b\right)-(1-p(\theta, z))\left(L+\left(\phi^{R P}-\phi^{R L}\right) b\right)\right] d F(z),
$$

the leader's marginal incentive for declaring war. The choice of the ruler matters only in case the adversary remains pacific. In that case, the upside of war, the income expansion associated with victory and the marginal effect of a victory on reselection, is traded off against the downside, the income loss plus the political cost of a loss. The relative magnitude of the two effects depends on the country's military capability:

Lemma 3.1 If the probability of retaining office is at least as large following a victory as it is following a defeat $\left(\phi^{R W} \geq \phi^{R L}\right)$, the ruler will attack if and only if military capability is sufficiently high.

\section{Proof.}

$$
v_{\theta}\left(\theta, q^{\prime}(z), \Phi^{R}\right)=\int_{\Theta} q^{\prime}(z) p_{\theta}(\theta, z)\left[B+L+\left(\phi^{R W}-\phi^{R L}\right) b\right] d F(z)>0
$$

by $p_{\theta}>0$ and by $\phi^{R W} \geq \phi^{R L}$ if $q^{\prime}(z)>0$ for a subset of $\Theta$ with positive measure. Hence, $q(\theta)=0$ if $\theta$ is sufficiently large and 1 otherwise.

The intuition is straightforward. The stronger is the army, the more (less) likely it is that the war will be won (lost). Since it is better to win a war than to lose it, the value of engaging in conflict increases with military power. Although this is a straightforward, almost trivial, theoretical result, there is a lack of consensus as to its empirical validity. Morgan and Campbell (1991) show that major democratic powers were involved in conflict less frequently than minor democratic powers in the period 1816-1976. Bueno de Mesquita and Lalman (1992: p.146-147) rely on this evidence when they propose "...the seeming paradox that the states most capable of winning in a violent confrontation are least likely to resort to that means of settling their differences". However, not only were the period's major democratic powers France, England and the USA, ${ }^{10}$ military powerful, they were even wealthy. As shown by Maoz and Russett (1993), wealth and conflict are negatively correlated. Therefore, it is plausible that the Morgan and Campbell (1991) study picks

\footnotetext{
${ }^{10}$ See Small and Singer (1982: 44-45) for the list of the major powers during the period 1816-1980 used by Morgan and Campbell (1991).
} 
up a significant wealth effect. Rousseau et.al. (1996) and Gelpi (1997) use data on the number of troops and the size of military expenditures to construct a measure of power. Their results confirm the proposition above: the likelihood that a country initiates the use of force against an adversary increases when the balance of power tips in its favour.

The fact that the net utility of declaring war is monotonic in military capacity has the implication that there for any set of beliefs about the opponent's actions, exists a cutoff point or trigger $\beta$ such that a country's leadership will declare war with certainty whenever military capability is above this threshold and remain peaceful otherwise, provided $\phi^{R W} \geq \phi^{R L}$. In order for beliefs to be consistent, each player must hold the belief that a threshold exists for the opponent too. Suppose that $\phi^{R^{\prime} W} \geq \phi^{R^{\prime} L}$ also holds, and that the expected trigger of the adversary is $\theta^{\prime}$. Impose this belief structure on (1) to obtain:

$$
v\left(\boldsymbol{\theta}, \Phi^{R}\right)=\int_{\underline{\theta}}^{\theta^{\prime}}\left[p(\theta, z)\left(B+\left(\phi^{R W}-\phi^{R P}\right) b\right)-(1-p(\theta, z))\left(L+\left(\phi^{R P}-\phi^{R L}\right) b\right)\right] d F(z) .
$$

$v\left(\boldsymbol{\theta}, \Phi^{R}\right)$ is the leadership's expected net benefit of going to war, given its capacity $\theta$, the belief that the enemy remains peaceful if and only if its military capacity is below $\theta^{\prime}$ and the replacement structure $\Phi^{R}$. For future reference, define the (implicit) function $\beta^{R}\left(\theta^{\prime}\right)$ in the following way:

$$
\begin{gathered}
\beta^{R}\left(\theta^{\prime}\right)= \begin{cases}\frac{\theta}{\beta^{R}} \mid v\left(\beta^{R}, \theta^{\prime}, \Phi^{R}\right)=0 & \text { if } v\left(\underline{\theta}, \theta^{\prime}, \Phi^{R}\right) \geq 0 \\
\bar{\theta} & \text { if } v\left(\bar{\theta}, \theta^{\prime}, \Phi^{R}\right)>0>v\left(\underline{\theta}, \theta^{\prime}, \Phi^{R}\right) \\
\text { if } v\left(\bar{\theta}, \theta^{\prime}, \Phi^{R}\right) \leq 0\end{cases} \\
\beta^{R}(\underline{\theta})=\lim _{\theta^{\prime} \downarrow \underline{\theta}} \beta^{R}\left(\theta^{\prime}\right) .
\end{gathered}
$$

$\beta^{R}(\cdot)$ is a continuous function defined on the compact space $\Theta$ by the assumptions on $p$ and $f$. It defines the trigger for which the ruler in a regime of type $R$ will attack as a function of the beliefs about the opponent's trigger. The threshold is an interesting object of study because it reveals the ex ante (i.e. before the revelation of military capabilities) likelihood that a country will attack another. The lower it is, the higher is the ex ante probability that the country will declare war.

Proposition 3.1 If the probability of retaining office is at least as large following a victory as it is following a defeat in both countries, the threshold for declaring war is increasing in the enemy's perceived threshold for conflict $\left(\beta_{\theta^{\prime}}^{R}\left(\theta^{\prime}\right)>0\right.$ for all $\left.\beta^{R} \in(\underline{\theta}, \bar{\theta})\right)$. 
Proof. $\beta_{\theta^{\prime}}^{R}=-v_{\theta^{\prime}} / v_{\theta} . v_{\theta}>0$ from the assumption that $\phi^{R W} \geq \phi^{R L}$, see Lemma 3.1. Hence, $\operatorname{sgn}\left\{\beta_{\theta^{\prime}}^{R}\right\}=-\operatorname{sgn}\left\{v_{\theta^{\prime}}\right\}$. Define two new variables,

$$
C^{R}=\frac{L+\left(\phi^{R P}-\phi^{R L}\right) b}{B+L+\left(\phi^{R W}-\phi^{R L}\right) b} \text { and } M\left(\boldsymbol{\theta}, C^{R}\right)=\int_{\underline{\theta}}^{\theta^{\prime}}\left[p(\theta, z)-C^{R}\right] d F(z) .
$$

By definition, $v\left(\boldsymbol{\theta}, \Phi^{R}\right)=\left(B+L+\left(\phi^{R W}-\phi^{R L}\right) b\right) M\left(\boldsymbol{\theta}, C^{R}\right)$, so $M\left(\beta^{R}, \theta^{\prime}, C^{R}\right)=0$ for all $\beta^{R} \in(\underline{\theta}, \bar{\theta})$. Perform an integration by parts:

$$
M\left(\beta^{R}, \theta^{\prime}, C^{R}\right)=\left[p\left(\beta^{R}, \theta^{\prime}\right)-C^{R}\right] F\left(\theta^{\prime}\right)-\int_{\underline{\theta}}^{\theta^{\prime}} p_{\theta^{\prime}}\left(\beta^{R}, z\right) F(z) d z=0 .
$$

$p_{\theta^{\prime}}\left(\beta^{R}, z\right)<0$ and $F(z)>0$ for all $z>\underline{\theta}$ imply $p\left(\beta^{R}, \theta^{\prime}\right)<C^{R}$ for all $\beta^{R} \in(\underline{\theta}, \bar{\theta})$ and $\theta^{\prime}>\underline{\theta}$. $v_{\theta^{\prime}}=\left(B+L+\left(\phi^{R W}-\phi^{R L}\right) b\right)\left[p\left(\beta^{R}, \theta^{\prime}\right)-C^{R}\right] f\left(\theta^{\prime}\right)<0$ completes the proof.

The proposition reveals that foreign policies display strategic complementarities; the likelihood of one leader being docile is increasing in the perception of the other leader as being docile. The explanation is the following. Each state leader knows that the opponent will attack him if and only if sufficiently powerful in terms of military capability (Lemma 3.1). Suppose now that the ruler, for some reason, is led to believe that the adversary has become more adverse to starting a conflict, i.e. the enemy's threshold value for attacking has increased. In the new state of the world the opponent will refrain from the use of force for some high levels of military capability at which he previously would have attacked. This is good news. It means that conflict can be avoided in some instances in which the war most likely would be lost. However, the only way the leader can take advantage of this opportunity is to abstain from the use of force himself. In this way peace fosters peace.

\section{The selectorate}

The first part of this section derives the optimal war probabilities from the viewpoint of the selectorate. The second part considers the question of whether reselection probabilities exist that implement the preferred war policy. The final part takes feasibility into account; the chosen policy is required to be time consistent.

Consider a representative member of the selectorate in regime $R$. Let $q^{\prime}(z)$ be the subjective belief that the foreign country will remain pacific as a function of its military capability $z \in \Theta$, and $q(\theta)$ the perceived likelihood that the ruler in the home country stays pacific as a function of 
military capability $\theta \in \Theta$. Expected utility is

$$
\begin{aligned}
U\left(q(\theta), q^{\prime}(z)\right)= & \int_{\Theta} \int_{\Theta}\left[q(\theta) q^{\prime}(z) I+\left(1-q(\theta) q^{\prime}(z)\right)(p(\theta, z)(I+B)\right. \\
& +(1-p(\theta, z))(I-L)-K)] d F(z) d F(\theta) .
\end{aligned}
$$

Differentiate $U$ with respect to $q(\theta)$ to find the selectorate's net incentive for declaring war

$$
u\left(\theta, q^{\prime}(z)\right)=\int_{\Theta} q^{\prime}(z)[p(\theta, z) B-(1-p(\theta, z)) L-K] d F(z)
$$

at military capability $\theta$. The selectorate strictly prefers the leader to attack the foreign country if and only if $u\left(\theta, q^{\prime}(z)\right)>0$. By remaining pacific, the selectorate saves on the cost $K$ of warfare and the income loss $L$ in case of defeat. On the negative side, the potential income gain $B$ is missed in cases where the war would in fact have been won. The incentive for declaring war depends on the country's military capability in an intuitive manner (the proof is analogous to the proof of Lemma 3.1 and thus omitted):

Lemma 4.1 The selectorate prefers war if and only if military capability is sufficiently high.

Each country thus has a trigger level above which they prefer war. Let $\theta^{\prime}$ be the anticipated trigger level of the foreign country. The net incentive for declaring war reduces to

$$
u(\boldsymbol{\theta})=\int_{\underline{\theta}}^{\theta^{\prime}}[p(\theta, z) B-(1-p(\theta, z)) L-K] d F(z) .
$$

For any anticipated threshold $\theta^{\prime}$ in the foreign country, the selectorate's preferred threshold level $\beta$ is found exactly at the point at which the selectorate is indifferent between war and peace, i.e., at $u\left(\beta, \theta^{\prime}\right)=0 .{ }^{11}$

The selectorate neither has the information nor sufficient instruments to instruct the leader to attack contingent on $\beta$. Instead, it is forced to use the ruler's strive for remaining in power to shape incentives. The question is whether reselection incentives are sufficient to align the preferences of the leader and the selectorate. Let $\Phi=\left\{\phi^{P}, \phi^{W}, \phi^{L}\right\}$ be any vector of reselection probabilities. With these instruments,

$$
v(\boldsymbol{\theta}, \Phi)-u(\boldsymbol{\theta})=\int_{\underline{\theta}}^{\theta^{\prime}}\left[p(\theta, z)\left(\phi^{W}-\phi^{P}\right) b-(1-p(\theta, z))\left(\phi^{P}-\phi^{L}\right) b+K\right] d F(z)
$$

\footnotetext{
${ }^{11} \beta$ is uniquely defined, and the selectorate prefers the implemented trigger to be as close to the preferred one as possible: $U$ is strictly quasi-concave in $\beta$ for any set of subjective beliefs $q^{\prime}\left(\theta^{\prime}\right)$.
} 
measures how the leader's incentive for declaring war deviates from the preferences of the selectorate. If $v(\boldsymbol{\theta}, \Phi)>u(\boldsymbol{\theta})$, the leader is too aggressive from the selectorate's point of view, if the difference is negative, he is too soft. The above expression also shows how the electorate can use $\Phi$ to align preferences. The higher are the post-conflict reselection probabilities $\phi^{W}$ and $\phi^{L}$, the more aggressive does the ruler tend to be. An increase in the pacific reselection probability $\phi^{P}$ induces a more pacific ruler.

Concerning the optimal reselection probabilities, consider first the case in which the cost of warfare is large, i.e. $K>b$. Assume also that the selectorate has chosen a policy so as to minimise the likelihood of war, i.e. $\phi^{W}=\phi^{L}=0$ and $\phi^{P}=1$. With these reselection probabilities, $v(\boldsymbol{\theta}, \Phi)-u(\boldsymbol{\theta})=(K-b) F\left(\theta^{\prime}\right)>0$. Even with the maximal punishment, certain replacement in case of war and certain reselection in case of peace, the leader still tends to pick wars too often. As the selectorate cannot do more to minimize the risk of war, $\phi^{W}=\phi^{L}=0$ and $\phi^{P}=1$ are optimal when wars are costly. Assume next that war is not so costly, i.e. $K \leq b$. Consider a policy in which the leader is reselected for sure if war does not break out, and is ousted with probability $K b^{-1}$ in every post-conflict state. In this case $v(\boldsymbol{\theta}, \Phi)=u(\boldsymbol{\theta})$ and preferences perfectly aligned. We have thus established:

Proposition 4.1 The following reselection policy is optimal: the leader is reselected for sure if peace prevails $\left(\phi^{P}=1\right)$ and is ousted with positive probability if war breaks out, irrespective of whether the war is won or lost $\left(\phi^{W}=\phi^{L}=\max \left\{1-K b^{-1} ; 0\right\}\right)$.

These reselection probabilities are the ones the selectorate would choose if able to commit to the policy. However, the set of policies is required to be sequentially rational. Under the assumptions of our model, the set of credible policies varies across regimes. Consider first the autocracy. The dictator knows that post-conflict political competition leads to full convergence between himself and any challenger. Moreover, replacing the incumbent is associated with significant costs to the selectorate. Knowing this, the dictator realizes that the selectorate is best off keeping the incumbent independently of his previous conflict management history. Reselection in all states of the world, therefore, is the unique sequentially rational replacement strategy in autocracy. Even in democracy political competition leads to full convergence between the incumbent and the challenger(s). However, voting for one candidate or the other is costless. As all candidates 
are associated with identical future policies, it is rational to replace the incumbent independently of the history. Hence, democracies can credibly replace their leaders and so the socially optimal policy is time consistent in democracy. We collect these result in a proposition:

Proposition 4.2 In equilibrium, the autocratic leader is always reselected $\left(\phi^{A P}=\phi^{A W}=\phi^{A L}=\right.$ 1). The democratic leader is reselected with certainty if and only if war has been avoided. Otherwise, he is replaced with positive probability $\left(\phi^{D P}=1\right.$ and $\left.\phi^{D W}=\phi^{D L}=\max \left\{1-K b^{-1} ; 0\right\}\right)$.

Several insights can be drawn from these results. First, one would expect democratic leaders to face a comparatively large risk of being replaced following war. This is consistent with findings (e.g. Bueno de Mesquita et.al., 1992 and 2003; Bueno de Mesquita and Siverson, 1995) that leaders in democracies tend to have a shorter post-war tenure than autocratic rulers. The theory further predicts post-war political survival in democracy to depend negatively, but the political survival in autocracy to be independent on the direct cost $K$ of conflict. Hence, one would expect the post-war tenure of democratic leaders to be more sensitive to the costs of conflict than that of autocratic leaders. Bueno de Mesquita et.al. (1992) and Bueno de Mesquita and Siverson (1995) find a negative relation between the per capita number of battle deaths and political survival, although they do not test the joint effect of democracy and cost of warfare.

The selectorate cannot benefit from conditioning the survival probability on the conflict outcome in this model. If war is costly $(K>b)$, the selectorate wants to minimize the probability that the leader attacks, which implies punishing him in all post-conflict states. If war is not so costly $(K \leq b)$, preferences can be perfectly aligned even without conditioning political survival on the war outcome. The model's prediction, that political survival is independent of the conflict outcome, is at odds with Bueno de Mesquita and Siverson (1995), Bueno de Mesquita, et.al. (2003) and Chiozza and Goeman's (2004) findings that conflict outcomes affect the tenure of political leaders. The model could be extended in at least three directions to generate outcome dependent reselection probabilities. First, the likelihood of winning a war could depend on some unobservable war-fighting capability or competence of the leader. If the selectorate values such a capability positively, a leader might have an incentive to launch a war to signal his war-fighting competence. In order to avoid incompetent leaders gambling for a lucky conflict outcome, the selectorate could benefit from rewarding good conflict outcomes and punishing bad ones. Second, 
the war outcome might depend on some unobservable war-fighting effort of the leadership. The selectorate would always prefer the leader to devote maximal effort into winning the war, although the leader might not. This moral hazard problem can be mitigated by reselecting the leader with higher probability in case of a win. The third extension can easily be incorporated into the current framework. Assume that the income loss $\bar{L}$ of the selectorate in case of defeat is larger than the corresponding income loss $L$ of the leader, i.e. $\bar{L}>L$. In this case, the leader tends to wage war too often. The following combination of reselection probabilities

$$
\phi^{W}-\phi^{L}=(\bar{L}-L) b^{-1}>0, \phi^{P}-\phi^{L}=(\bar{L}-L+K) b^{-1}>0
$$

leads to full alignment of preferences, $v(\boldsymbol{\theta}, \Phi)=u(\boldsymbol{\theta})$, in the case $b \geq K+\bar{L}-L$.

Note finally, that the leadership's incentives for going to war may vary also across democratic institutions. In a presidential system with term limits, for example, the reselection probability is zero in the final term, independently of policy outcomes, i.e. $\Phi^{D}=\mathbf{0}$. Here, $v(\boldsymbol{\theta}, \mathbf{0})-u(\boldsymbol{\theta})=$ $K F\left(\theta^{\prime}\right)>0$, and so the model predicts an excessive incentive for going to war in the final term. I am not aware of any study which tests how term limits affect foreign policy behaviour. Chiozza and Goeman (2004) report a negative correlation between tenure and the extent of international crises in presidential democracies, although the results are statistically insignificant.

\section{War}

This section is concerned with the main issue of the paper, the likelihood of international conflict. Recall from the previous section that the autocratic and democratic selectorates optimally set reselection probabilities such that the post-war likelihood of reselection is independent of whether the war was lost or won. This has two implications for the rulers' propensity to attack the foreign country: $(i)$ the leader will attack if and only if military capability is sufficiently high, see Lemma 3.1 ; $(i i)$ the propensity to attack is decreasing in the adversary's perceived threshold for declaring war, see Proposition 3.1.

Figure 1 is a mapping of the two countries' best reply functions. Suppose the leadership in the home country (henceforth $R$ ) ascertains that the foreign (henceforth $R^{\prime}$ s) strategy is to attack whenever his military capacity rises above $y . z=\beta^{R}(y)$ defines the level at which $R$ is indifferent 
between war and peace, given the beliefs about the opponent's actions. Thus the best reply to $R^{\prime} \mathrm{s}$ strategy is to "attack iff $\theta>z "$. $(z, y)$ cannot be an equilibrium. $R^{\prime}$ s best reply to $R$ s strategy "attack iff $\theta>z "$ is "attack iff $\theta^{\prime}>x " . x \neq y$ renders strategies inconsistent. $\boldsymbol{\theta}^{*}=\left(\theta^{*}, \theta^{*}\right)$, on the other hand, constitutes a vector of equilibrium threshold values, since "attack iff $\theta>\theta^{*}$ " is $R$ s best reply to $R^{\prime}$ s strategy "attack iff $\theta^{\prime}>\theta^{* *}$ and vice versa. In view of the arguments above, the following lemma is obvious:

Lemma 5.1 Any BNE of the conflict game is a vector $\boldsymbol{\theta}^{*}$ of equilibrium thresholds such that $\theta^{*}=\beta^{R}\left(\theta^{*}\right)$ and $\theta^{*}=\beta^{R^{\prime}}\left(\theta^{*}\right)$.

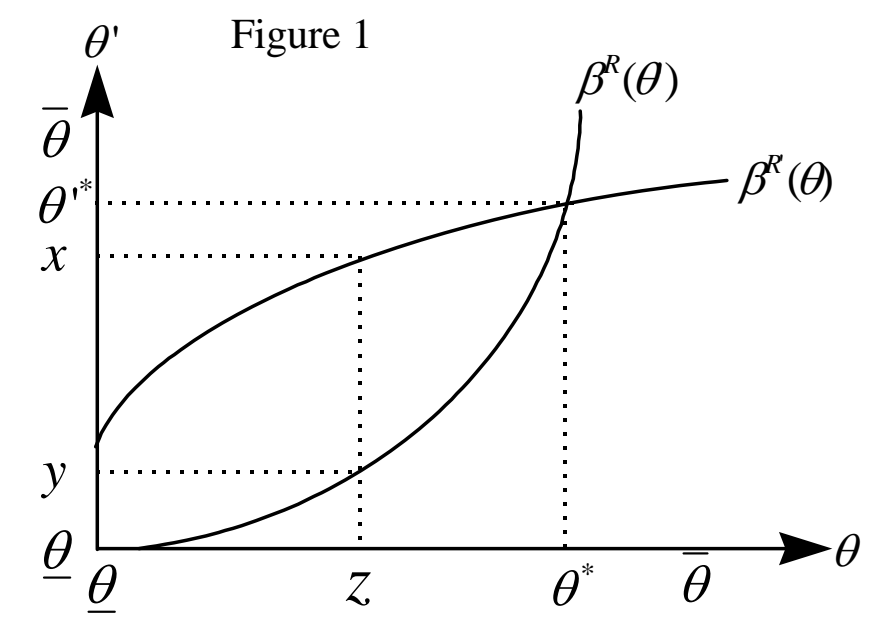

We are now ready to analyse the types of conflict equilibria that arise in this model. First, if both rulers are convinced that the adversary will declare war no matter what, one's own actions do not matter, there will be war anyway. Hence, "always declare war" is a best response to the adversary's strategy "always declare war". Consequently:

Proposition 5.1 Always declare war constitutes a BNE.

This is a negative result and if it were to be the unique equilibrium outcome of the model, the model would be flawed since countries do not find themselves constantly involved in violent interstate conflicts. Let a Partially Pacific Equilibrium (abbreviated PPE) be defined as an equilibrium with a positive (ex ante) probability of peace, i.e. with $F\left(\theta^{*}\right) F\left(\theta^{\prime *}\right)>0$. The following shows that PPE exist under fairly general symmetry assumptions: 
Proposition 5.2 For any dyad, if (i) the conflict technology is symmetric, in the sense that $p(\underline{\theta}, \underline{\theta})=1 / 2$, and (ii) the income loss $L$ in case of defeat is at least as large as the income gain $B$ in case of a win, $L \geq B$, there exists at least one PPE.

Proof. Recall the definitions of $C^{R}$ and $M^{R}\left(\boldsymbol{\theta}, C^{R}\right)$ in (3). First, I show that a PPE exists in the $R R^{\prime}$ dyad if $p(\underline{\theta}, \underline{\theta})=1 / 2$ and $\min \left\{C^{R}, C^{R^{\prime}}\right\} \geq 1 / 2$. Note that

$$
\begin{aligned}
M\left(\theta^{\prime}, \theta^{\prime}, C^{R}\right) & =\int_{\underline{\theta}}^{\theta^{\prime}}\left[p\left(\theta^{\prime}, z\right)-C^{R}\right] d F(z) \\
& =\int_{\underline{\theta}}^{\theta^{\prime}}\left[p\left(\theta^{\prime}, z\right)-C^{R}\right] d F(z)+p\left(\theta^{\prime}, \underline{\theta}\right) F\left(\theta^{\prime}\right)-p\left(\theta^{\prime}, \underline{\theta}\right) F\left(\theta^{\prime}\right) \\
& =\left(p\left(\theta^{\prime}, \underline{\theta}\right)-C^{R}\right) F\left(\theta^{\prime}\right)+\int_{\underline{\theta}}^{\theta^{\prime}} \int_{\underline{\theta}}^{z} p_{\theta^{\prime}}\left(\theta^{\prime}, y\right) d y d F(z) .
\end{aligned}
$$

The second term on the last line is negative for all $\theta \prime>\underline{\theta}$ and the first term becomes non-positive as $\theta^{\prime}$ converges to $\underline{\theta}$ by the assumption that $p(\underline{\theta}, \underline{\theta})=\overline{1} / 2$ and $C^{R} \geq 1 / 2$. Thus, for $C^{R} \geq 1 / 2$ $\exists \theta^{\prime c}>\underline{\theta}$ such that $M\left(\theta^{\prime}, \theta^{\prime}, C^{R}\right)<0$ for all $\theta^{\prime} \in\left[\underline{\theta}, \theta^{\prime c}\right]$, and consequently $\beta^{R}\left(\theta^{\prime}\right)>\theta^{\prime} \forall \theta^{\prime} \in\left[\underline{\theta}, \theta^{\prime c}\right]$ by $M_{\theta}>0$. By the same argument there exists $\theta^{c}>\underline{\theta}$ with symmetric properties, i.e. $\beta^{R^{\prime}}(\theta)>\theta$ $\forall \theta \in\left[\underline{\theta}, \theta^{c}\right]$. Let $a=\min \left\{\theta^{c}, \theta^{\prime c}\right\}$. Consider the continuous mapping $h(z)=\beta^{R}\left(\beta^{R^{\prime}}(z)\right)-z$. By Lemma 5.1, $\boldsymbol{\theta}^{*}$ constitutes an equilibrium if $h\left(\theta^{*}\right)=0$ and $\theta^{* *}=\beta^{R^{\prime}}\left(\theta^{*}\right)$. $\beta^{R}(a)>a, \beta^{R^{\prime}}(a)>a$ and $\beta_{\theta^{\prime}}^{R}\left(\theta^{\prime}\right) \geq 0$ imply $\beta^{R}\left(\beta^{R^{\prime}}(a)\right) \geq \beta^{R}(a)>a$, hence $h(a)>0$. Moreover, $\beta^{R} \in[\underline{\theta}, \bar{\theta}]$ implies $h(\bar{\theta}) \leq 0$. It follows from the Mean-Value Theorem that there exists a $\theta^{*}>a>\underline{\theta}$, such that $h\left(\theta^{*}\right)=0$. Moreover, $\theta^{*}=\beta^{R^{\prime}}\left(\theta^{*}\right) \geq \beta^{R^{\prime}}(a)>a>\underline{\theta}$. Finally, $F\left(\theta^{*}\right) F\left(\theta^{*}\right)>0$ by $f(\cdot)>0$. This completes the first part of the proof. Utilising the equilibrium $\Phi^{R}$, see Proposition $4.2, C^{D} \geq 1 / 2$ is equivalent to $2 \max \left\{K b^{-1} ; 1\right\} b+L \geq B$ and $C^{A} \geq 1 / 2$ is equivalent to $L \geq B$.

If the income loss $L$ outweighs the income gain $B$, and the conflict technology is symmetric, a country will attack only if it has an expected military advantage over the adversary. This requirement of military superiority is indicated in Figure 1 as $\beta^{R}(\underline{\theta})>\underline{\theta}$ and $\beta^{R^{\prime}}(\underline{\theta})>\underline{\theta}$. Therefore, an equilibrium exists in which both countries remain pacific if they are sufficiently weak. The remainder of the paper assumes the existence of PPE.

The conflict game has multiple equilibria, and so the problem of equilibrium selection arises. This paper restricts attention to the properties of the Maximal Equilibrium (ME), that is, the equilibrium that maximizes the likelihood of a peaceful outcome. I show in an appendix (available on request) that the ME satisfies two standard equilibrium selection criteria, pay-off dominance and risk-dominance (Harsanyi and Selten, 1988). Every ruler prefers the adversary to be as pacific as possible because one always has the option of going to war. Therefore, the ME pay-off dominates every other equilibrium. If uncertainty exists about the adversary's threshold strategy, playing 
a soft strategy provides a higher expected payoff. War can then be avoided in circumstances it might otherwise have been lost, i.e. when the opponent is strong. Therefore, the ME strategy risk-dominates any other equilibrium threshold strategy. The following characterization is the main result of the paper:

Proposition 5.3 The likelihood of war in the Maximal Equilibrium is (i) lowest in the democratic dyad, highest in the autocratic dyad, with the mixed dyad in between; (ii) increasing in the benefit $B$ of winning and decreasing in the cost $L$ of losing the war; (iii) decreasing in the benefit $b$ of holding office and the direct cost $K$ of warfare if and only if at least one of the countries in the dyad is democratic.

Proof. I first prove the existence of a Maximal Equilibrium (ME) $\boldsymbol{\theta}^{m}=\left(\theta^{m}, \theta^{m \prime}\right)$, assuming that PPE do exist. Define the function $\gamma(\boldsymbol{\theta})=\left(\beta^{R}\left(\theta^{\prime}\right)-\theta, \beta^{R^{\prime}}(\theta)-\theta^{\prime}\right)$. It is continuous by continuity of $\beta^{D}$ and $\beta^{A}$. Write $\Theta^{*} \subset \Theta^{2}$ the non-empty set of equilibrium thresholds and $\Theta^{c}=$ $\left\{\boldsymbol{\theta} \in \Theta^{2} \mid \boldsymbol{\gamma}(\boldsymbol{\theta}) \neq \mathbf{0}\right\}$ the complement of $\Theta^{*}$. By definition $\boldsymbol{\theta}^{m} \in \arg \max _{\boldsymbol{\theta}^{*} \in \Theta^{*}} F\left(\theta^{*}\right) F\left(\theta^{\prime *}\right)$. F $(\cdot)$ is continuous, so the maximization program has a solution if $\Theta^{*}$ is compact. By continuity of $\gamma \exists$ a neighborhood $N(\boldsymbol{\theta}, r)$ around every $\boldsymbol{\theta} \in \Theta^{c}$, such that $\gamma(\mathbf{z}) \neq \mathbf{0} \forall \mathbf{z} \in N(\boldsymbol{\theta}, r)$. Thus, $\Theta^{c}$ is an open set, rendering $\Theta^{*}$ closed. $\Theta^{*}$ is a closed subset of the compact set $\Theta^{2}$, hence itself compact.

I next consider the comparative statics of the ME. I first show that any parameter which makes a country less aggressive (increases the threshold for conflict), leads to a lower likelihood of conflict in ME. This result is due to strategic complementarity. All parameter changes affect the likelihood of conflict through $C^{R}$ (see the proof of Proposition 3.1). Since some parameters $(I, B$ and $L$ ) affect both countries simultaneously, it is necessary to consider their joint effect. Compare two states of the world $\mathbf{C}_{1}=\left(C_{1}, C_{1}^{\prime}\right)$ and $\mathbf{C}_{2}=\left(C_{2}, C_{2}^{\prime}\right)$ and assume without loss of generality that $C_{1}<C_{2}$ and $C_{1}^{\prime} \leq C_{2}^{\prime}$. Let $\beta^{1}(z)$ and $\beta^{2}(z)$ be the home country's threshold levels of conflict in the two situations $\mathbf{C}_{1}$ and $\mathbf{C}_{2}$, respectively, given the belief that the foreign country's threshold level of conflict is $z$. $\beta^{\prime 1}(z)$ and $\beta^{\prime 2}(z)$ are defined similarly. Write $\boldsymbol{\theta}^{m}=\left(\theta^{m}, \theta^{\prime m}\right)$ the ME in the first state, and let $\boldsymbol{\theta}^{*}=\left(\theta^{*}, \theta^{*}\right)$ be an equilibrium in the second state. Define the function $h^{\prime 2}(z)=\beta^{\prime 2}\left(\beta^{2}(z)\right)-z . \boldsymbol{\theta}^{*}$ is an equilibrium in the second state if $h^{\prime 2}\left(\theta^{\prime *}\right)=0$ and $\theta^{*}=\beta^{2}\left(\theta^{\prime *}\right)$. We show below that there exists an equilibrium $\boldsymbol{\theta}^{*}$ such that $\theta^{*} \geq \theta^{m}$ and $\theta^{\prime *} \geq \theta^{m}$.

Since $\beta(\cdot)$ shifts upward with upward shifts in $C^{R}$, it follows that $\beta^{2}\left(\theta^{\prime m}\right) \geq \beta^{1}\left(\theta^{\prime m}\right) \equiv \theta^{m}$ (with strict inequality if $\theta^{m}<\bar{\theta}$ ). Invoking Proposition 3.1, one further obtains $\beta^{\prime 1}\left(\beta^{2}\left(\theta^{\prime m}\right)\right) \geq$ $\beta^{\prime 1}\left(\theta^{m}\right) \equiv \theta^{\prime m}$ (with strict inequality if $\theta_{1}^{m}<\bar{\theta}$ and $\left.\theta_{2}^{m}<\bar{\theta}\right)$. Finally, $\beta^{\prime 2}\left(\beta^{2}\left(\theta^{\prime m}\right)\right) \geq \beta^{\prime 1}\left(\beta^{2}\left(\theta^{\prime m}\right)\right)$ by $C_{1}^{\prime} \leq C_{2}^{\prime}$. Summarize all these effects to obtain $h^{\prime 2}\left(\theta^{\prime m}\right) \geq 0$ (with strict inequality if $\theta^{m}<\bar{\theta}$ and $\left.\theta^{\prime m}<\bar{\theta}\right)$. Note next that $h^{\prime 2}(\bar{\theta}) \leq 0$ since $\beta^{\prime 2}(z) \in[\underline{\theta}, \bar{\theta}]$. Thus, from the Mean-Value Theorem there exists $\theta^{\prime *} \in\left[\theta^{\prime m}, \bar{\theta}\right]$ such that $h^{\prime 2}\left(\theta^{\prime *}\right)=0\left(\theta^{\prime *}>\theta^{\prime m}\right.$ if $\theta^{m}<\bar{\theta}$ and $\left.\theta^{\prime m}<\bar{\theta}\right)$. $\theta^{\prime *} \geq \theta^{m}$ implies $\theta^{*}=\beta^{2}\left(\theta^{\prime *}\right) \geq \beta^{1}\left(\theta^{\prime *}\right) \geq \beta^{1}\left(\theta^{\prime m}\right) \equiv \theta^{m}$ (the inequality is strict if $\theta^{m}<\bar{\theta}$ and $\left.\theta^{m}<\bar{\theta}\right)$.

Turning to the comparative statics results, one only needs to demonstrate the partial effects. Result $(i), \beta^{A}\left(\theta^{\prime}\right) \leq \beta^{D}\left(\theta^{\prime}\right): v\left(\beta^{D}, \theta^{\prime}, \Phi^{A}\right)-v\left(\beta^{D}, \theta^{\prime}, \Phi^{D}\right)=\max \left\{K b^{-1} ; 1\right\} b F\left(\theta^{\prime}\right)>0$ and $v_{\theta}\left(\boldsymbol{\theta}, \Phi^{A}\right)>0$ imply $\bar{\beta}^{A}\left(\theta^{\prime}\right)<\beta^{D}\left(\theta^{\prime}\right)$ for all $\beta^{A} \in(\underline{\theta}, \bar{\theta})$. Results (ii) and (iii): Plug the equilibrium values of $\Phi^{R}$ into $v\left(\beta^{R}, \theta^{\prime}, \Phi^{R}\right)$ to get

$$
v^{R}\left(\beta^{R}, \theta^{\prime}, \Phi^{R}\right)=\int_{\underline{\theta}}^{\theta^{\prime}}\left[p\left(\beta^{R}, z\right) B-\left(1-p\left(\beta^{R}, z\right)\right) L-I^{R} \min \left\{K b^{-1} ; 1\right\} b\right] d F(z)=0,
$$


where $I^{R}$ is an indicator function, $I^{D}=1$ and $I^{A}=0$. By implicit differentiation, $\operatorname{sgn}\left\{\beta_{B}^{R}\right\}=$ $-\operatorname{sgn}\left\{v_{B}^{R}\right\}<0, \operatorname{sgn}\left\{\beta_{L}^{R}\right\}=-\operatorname{sgn}\left\{v_{L}^{R}\right\}>0, \operatorname{sgn}\left\{\beta_{b}^{R}\right\}=-I^{R} \operatorname{sgn}\left\{v_{b}^{R}\right\} \geq 0, \operatorname{sgn}\left\{\beta_{K}^{R}\right\}=-I^{R} \operatorname{sgn}\left\{v_{K}^{R}\right\} \geq$ 0 , which completes the proof.

Strategic interaction between the countries has the consequence that changes in one country affect both countries. However, partial effects are transformed into equilibrium effects in a predictable manner. Any change in an underlying parameter that makes a country more reluctant to initiating conflict is reinforced by a strategic effect by which even the opponent becomes increasingly reluctant to starting a war. This result is an implication of the peace fosters peace Proposition 3.1 which establishes pacific behaviour as strategic complements.

Democracies are universally more pacific than autocracies owing to the electorate's unique possibility to punish opportunistic behaviour by the democratic country's leaders. The democracy's higher threshold for initiating conflict spills over to the adversary through the strategic complementarity. Consequently, increasing the number of democracies in the dyad leads to a lower equilibrium likelihood of war.

In addition to accounting for the empirical regularity that democratic dyads are more pacific than other dyads, the model sheds some light on the intriguing observation (Bueno de Mesquita and Siverson, 1995; Reiter and Stam, 1998) that democracies tend to win more of the wars they initiate than non-democracies do. As the democratic threshold in terms of military capability is higher than the autocratic threshold, the conflict initiating democracy on average has a higher military capability than a conflict initiating autocracy, all other things held equal. Democracies on average win more of the wars they start because they are more selective about the wars they initiate than autocracies.

An interesting implication of the additional comparative statics results above, is that an autocratic leader's incentive for waging war might be more sensitive to the potential cost of conflict in the target country than in the home country. As the autocratic leader cannot be punished ex post, he cannot be forced to internalise his selectorate's cost of conflict, hence he could be expected to be largely negligent about it. If the target country is a democracy, the dictator knows that the democratic leader will be less reluctant to starting a war the higher are the costs of conflict. Due to strategic complementarity, this reluctancy spills over to the autocratic ruler, who also becomes less inclined to go to war. Hence, the autocratic ruler to a certain extent internalises the cost of conflict in the foreign country. Plausible or not, this result points to a key aspect of dyadic theory. 
Factors that affect the likelihood that one country initiates a conflict affect all countries, not just the country in which the change has taken place.

\section{Conclusion}

This paper has developed a simple theory of democracy and autocracy and applied it to a twocountry conflict game in which state leaders simultaneously decide whether or not to attack the other country. In democracy, the leader can be costlessly replaced in general elections, whereas autocratic leaders can be replaced only at considerable cost to the selectorate. War is more costly to the selectorate than to the leader. Hence, the ruler has an inclination to wage war too often, in democracy as well as in autocracy. The ability to costlessly reward the political leadership through reselection provides a mechanism by which the democratic selectorate can control the actions of the leadership to an extent which is impossible in autocracy.

The theory predicts that democratic leaders, for the fear of being thrown out of office, tend to be more selective about engaging in war than autocratic leaders and are more sensitive to the costs of warfare. In terms of military capability, the threshold for initiating conflict is higher in democracy than autocracy. It has been shown that policies are strategic complements. The perception of one country as being pacific renders the adversary more pacific, too. Consequently, democratic dyads are more pacific than autocratic dyads, with mixed dyads in between. Further, the likelihood of war is increasing in the potential gain of winning a conflict, decreasing in the potential loss of defeat, in the benefit of holding office and in the direct cost of conflict.

The model emphasizes the importance of strategic spillover effects. Domestic factors that serve to reduce the danger of a country initiating conflict also serve to reduce the likelihood of foreign conflict initiation. These spillover effects have implications for empirical testing. Empirical analysis of conflict initiation should control not only for domestic factors, but also for the characteristics of the potential target beyond estimators of military balance and regime type. Second, the model predicts that the ruler's sensitivity to domestic factors sometimes depends on the regime type, e.g. democratic regimes are more sensitive to the costs of conflict than dictators. One should therefore take account of joint effects in the empirical specification. 


\section{References}

[1] Babst, Dean (1964): "Elective governments: a force for peace," Wisconsin Sociologist 3: 9-14.

[2] Baliga, Sandeep, David O. Lucca and Tomas Sjöström (2007): "Domestic political survival and international conflict: is democracy good for peace?", mimeo, Northwestern University.

[3] Bester, Helmut and Karl Wärneryd (2006): "Conflict and the social contract," Scandinavian Journal of Economics 108: 231-249.

[4] Bremer, Stuart A. (1992): "Dangerous dyads: conditions affecting the likelihood of interstate war, 1816-1965," Journal of Conflict Resolution 36: 309-341.

[5] Bueno de Mesquita, Bruce and David Lalman (1992): War and Reason, New Haven, CT: Yale University Press.

[6] Bueno de Mesquita, Bruce and Randolph M. Siverson (1995): "War and the survival of political leaders: a comparative study of regime types and political accountability," American Political Science Review 89: 841-855.

[7] Bueno de Mesquita, Bruce, Randolph M. Siverson and Gary Woller (1992): "War and the fate of regimes: a comparative analysis," American Political Science Review 86: 638-646.

[8] Bueno de Mesquita, Bruce, James D. Morrow, Randolph M. Siverson and Alastair Smith (1999): "An institutional explanation of the democratic peace," American Political Science Review 93: 791-807.

[9] Bueno de Mesquita, Bruce, Alastair Smith, Randolph M. Siverson and James D. Morrow (2003): The Logic of Political Survival, Cambridge, MA: MIT Press.

[10] Chan, Steve (1984): "Mirror, mirror on the wall...are the freer countries more pacific?" Journal of Conflict Resolution 28: 617-648.

[11] Chiozza, Giacomo and H.E. Goemans (2004): "International conflict and the tenure of leaders: is war still ex post inefficient?," American Journal of Political Science 48: 604-619.

[12] Downs, George W. and David M. Rocke (1994): "Conflict, agency and the gambling for resurrection: the principal-agent model goes to war," American Journal of Political Science 38: $362-380$.

[13] Garfinkel, Michelle (1994): "Domestic politics and international conflict," American Economic Review 84: 1294-1309.

[14] Gelpi, Christopher (1997): Democratic diversions: governmental structure and the externalization of domestic conflict, Journal of Conflict Resolution 41: 255-282.

[15] Gurr, Ted R. (1974): "Persistence and change in political systems 1800-1971," American Political Science Review 68: 1482-1504.

[16] Harsanyi, John C. and Reinhard Selten (1988): A General Theory of Equilibrium Selection in Games, Cambridge, MA: MIT Press.

[17] Hess, Gregory D. and Athanasios Orphanides (1995): "War politics: an economic, rationalvoter framework," American Economic Review 85: 828-846.

[18] Hess, Gregory D. and Athanasios Orphanides (2001): "War and democracy," Journal of Political Economy 109: 776-810. 
[19] Huntington, Samuel P. (1989): "No exit: the errors of endism," The National Interest 17: 3-11.

[20] Huth, Paul and Bruce Russett (1993): "General deterrence between enduring rivals: testing three competing models," American Political Science Review 87: 61-73.

[21] Jackson, Matthew O. and Massimo Morelli (2007): "Political bias and war," American Economic Review 97: 1353-73.

[22] Leeds, Brett A. (1999): "Domestic political institutions, credible commitments, and international cooperation," American Journal of Political Science 43: 979-1002.

[23] Leeds, Brett A. and David R. Davis (1999): "Beneath the surface: regime type and international interaction," Journal of Peace Research 36: 5-21.

[24] Levy, Gilat and Ronny Razin (2004): "It takes two: an explanation for the democratic peace," Journal of the European Economic Association 2: 1-29.

[25] Maoz, Zeev and Nasrin Abdolali (1989): "Regime types and international conflict, 1816-1976," Journal of Conflict Resolution 33: 3-35.

[26] Maoz, Zeev and Bruce Russett (1992): "Alliance, contiguity, wealth and political stability: is the lack of conflict among democracies a statistical artifact?," International Interactions 17: 245-267.

[27] Maoz, Zeev and Bruce Russett (1993): "Normative and structural causes of democratic peace, 1946-1986," American Political Science Review 87: 624-638.

[28] Morgan, T. Clifton and Sally H. Campbell (1991): "Domestic structure, decisional constraints and war: so why Kant democracies fight?" Journal of Conflict Resolution 35: 187-211.

[29] Mueller, John (1989): Retreat from Doomsday: The Obsolence of Major War, New York: Basic Books.

[30] Oneal, John R., Frances H. Oneal, Zeev Maoz and Bruce Russett (1996): "The liberal peace: interdependence, democracy, and international conflict, 1950-85," Journal of Peace Research 33: $11-28$.

[31] Peceny, Mark, Caroline C. Beer and Shannon Sanchez-Terry (2002): "Dictatorial peace?" American Political Science Review 96: 15-26.

[32] Ray, James Lee (1989): Global Politics, 4th ed. Boston, MA: Houghton Mifflin.

[33] Reiter, Dan (1995): "Exploding the powder keg myth: preemptive wars almost never happen," International Security 20: 5-34.

[34] Reiter, Dan and Allan C. Stam III (1998): "Democracy, war initiation and victory," American Political Science Review 92: 377-389.

[35] Richards, Diana, T. Clifton Morgan, Rick Wilson, Valerie Schwebach and Gary Young (1993): "Good times, bad times and the diversionary use of force: a tale of some not-so-free agents," Journal of Conflict Resolution 37: 504-535.

[36] Rousseau, David L., Christopher Gelpi, Dan Reiter and Paul K. Huth (1996): "Assessing the nature of the democratic peace, 1918-88," American Political Science Review 90: 512-533.

[37] Shirk, Susan (1993): The Political Logic of Reform in China, Berkeley, CA: University of California Press. 
[38] Small, Melvin and J. David Singer (1982): Resort to Arms: International and Civil Wars, 1816-1980, Beverly Hills, CA: Sage Publications.

[39] Smith, Alastair (1993): Diversionary foreign policy in democratic systems, International Studies Quarterly 40: 133-153.

[40] Ward, Michael D. Randolph M. Siverson and Xun Cao (2007): "Disputes, democracies and dependencies: a reexamination of the Kantian peace," American Journal of Political Science 51: 583-601.

[41] Werner, Suzanne (2000). "The effects of political similarity on the onset of militarized disputes, 1816-1985," Political Research Quarterly 53: 343-374.

[42] Wintrobe, Ronald (1998): The Political Economy of Dictatorship, Cambridge: Cambridge University Press. 